\title{
Prevalence of lower limb deformities among primary school students
}

\author{
Sahar Saad Ganeb1', Sami El-Said Egaila', Abdelmoniem Abdelfattah Younis², Asmaa Moheiy Abd El-Aziz ${ }^{3}$ and
} Nashwa Ismail Hashaad ${ }^{1 *}$ (D)

\begin{abstract}
Background: Lower limb deformities could affect child's quality of life and may worsen with time. This work aims to study the prevalence of lower limb deformities among primary school students in our governorate.

Methods: This cross-sectional descriptive study was carried out on 4689 students attending 12 public primary schools during the academic year 2019-2020.Complete clinical examination was done for picking of cases of genu varum, genu valgum, genu recurvatum, flat foot, pes cavus, hallux valgus, in-toeing, and lower limb discrepancy, and $x$-ray on both feet, pelvis, and full-length lower limb was requested.

Results: This cross-sectional descriptive study included 4689 students. The prevalence of lower limb (LL) deformities was $16.61 \%$. One hundred twenty-three (2.62\%) children had a positive history of musculoskeletal pain, $0.09 \%$ had genu varum, $0.11 \%$ had genu valgum, $0.75 \%$ had Genu recurvatum, $0.03 \%$ had LL discrepancy, $13.86 \%$ had flexible flat foot, $1.22 \%$ had rigid flat foot, $0.23 \%$ had pes cavus, $1.04 \%$ had in-toeing, $0.06 \%$ had hallux varus, and $0.11 \%$ had hallux valgus.

Conclusions: Lower limb deformities are a considerable problem in primary school students that need early diagnosis because it could affect child's future, health, and career. Further studies are needed to investigate spinal deformity, vit D level, calcium level, foot wear, and school bag weight as hidden factors.
\end{abstract}

Keywords: Lower limb deformities, Children, Prevalence, Schools

\section{Background}

Lower limb (LL) deformities are common among pediatric population. Though some of them are typical for some periods of growth and development, others could result in serious health problems and reduced quality of life [1]. Deformities could start in childhood and their harmful effects may continue till adulthood [2]. LL deformity causes mechanical load maldistribution and mass center functional alterations and requires adaptation to the new body scheme creating many vectors across multiple joints [3]. Prevalence of postural deformities has increased significantly over the past decades due to life pattern modification ranging from 10

\footnotetext{
* Correspondence: Zeinahashaad@yahoo.com

${ }^{1}$ Rheumatology, Rehabilitation \& Physical Medicine Department, Faculty of Medicine, Benha University, Benha 13115, Egypt

Full list of author information is available at the end of the article
}

to $70 \%$. Physical inactivity, playing electronic games, heavy backpacks, and prolonged unhealthy diet have been demonstrated in this regard [4].Genu varum predisposes an individual to various injuries and weakening of the articular cartilage as force line shifts farther medially away from joint center generating a medial joint reaction force that is nearly three and a half times that of the lateral compartment being a risk factor for the development of the patellofemoral pain syndrome in athletes and osteoarthritis later in life [5].New-born is usually described as having physiological genu valgum, around 18 to 24 months; the tibiofemoral angle (TFA) variation aligns to $0^{\circ}$ then reaches the maximum deviation value of $12^{\circ}$ at 3 years and decreases until it stabilizes at 5 to $6^{\circ}$ by 6 or 7 years of age [6], so in children aging 2 to 6 years, valgus knee is normal within certain limits of knee angle, therefore being characterized as physiological, and 
most of children presenting this condition at these ages have spontaneous correction [7]. Foot posture acts a pivotal role in lower limb performance. Flexible flat foot (FFF) fade with non-weight-bearing and infrequently requires treatment, even though overuse may cause pain meanwhile rigid FF occurs due to acquired or congenital factors as collagen disorders, trauma, spastic conditions, or neuromuscular conditions [8]. Hallux valgus may be induced by genetics, pes planus, metatarsus primus varus, first metatarsal length, and hypermobility of the metatarsocuneiform joint. Also, unfit shoes seem to be a major extrinsic factor [9]. Lower limb (LL) discrepancy is one of the common musculoskeletal deformities which may be complicated by scoliosis [10]. In-toeing is caused by a rotational variation anywhere in the lower extremity that causes the foot to point inward like metatarsus adductus, internal tibial torsion, and femoral anteversion [11]. This work aims to study the prevalence of lower limb deformities among primary school students in our governorate.

\section{Methods Study design}

This cross-sectional descriptive study was carried out on 4689 students attending 12 public primary schools during the academic year 2019-2020. Students with a known history of rheumatic fever, juvenile idiopathic arthritis, juvenile dermatomyositis, juvenile systemic lupus erythematosus, lower limb weakness, or paralysis were excluded. A written consent was obtained from the parents of each student. Permission was gotten from the Ministry of Education. Ethical committee of Faculty of Medicine of our university approved this study.

\section{Sample size determination}

In total, 707,503 primary school children were registered as students in private and government schools by the local government school authority bureau. The required sample size was calculated using Epi Info software version 7.0 (Centers for Disease Control and Prevention, USA) and was based on this registered population. The following assumptions were used to determine the sample size based on single population proportion: prevalence of $50 \%$ since there is a widely variable prevalence rate in epidemiological studies, confidence level of $95 \%$, and design effect of 1 required sample size was $n=384$.

Sample size was calculated using Epi Info software version 7.0 (Centers for Disease Control and Prevention, USA).

\section{Clinical assessment}

Our students' demographic data were documented; they were subjected to full history taking and thorough clinical examination. Musculoskeletal symptoms in different body regions were assessed using an Arabic translation of 1st part of the standardized Nordic questionnaires for musculoskeletal symptoms [12]. Their heights and weights were assessed in a standing position with light cloths. According to the Centers for Disease Control and Prevention (CDC) body mass index (BMI) calculator for children and teens, BMI was calculated as follows: weight $(\mathrm{kg}) /$ height squared $\left(\mathrm{m}^{2}\right)$. It was then used to find the corresponding BMI-for-age percentile on a growth chart for the child's age and sex, and the children were categorized as underweight and normal weight [13]. Our students were evaluated from anterior, posterior, medial, and lateral aspects. Using a goniometer, lateral tibiofemoral angle (lateral TFA) was measured. With both knees or ankles touching using a tape, intercondylar (ICD) and intermalleolar (IMD) distances were measured. Intermalleolar distance in our studentś age group up to $8 \mathrm{~cm}$, intercondylar distance up to $5 \mathrm{~cm}$, and tibiofemoral angle up to $12^{\circ}$ are documented as normal [14]. From the inferior aspect of the anterior superior iliac spine (ASIS) to the inferior aspect of the medial malleolus, the actual limb length was measured [15]. To measure hindfoot valgus, the angle between longitudinal axes of the Achilles tendon and calcaneus was used [16]. Longitudinal arch angle (LAA) defined as the superior angle formed by two vectors: one passing through the midpoint of the medial malleolus to the navicular tuberosity and the other passing through the midpoint of the medial aspect of the first metatarsal head to the navicular tuberosity [17]. If the child's plantar arch appeared flat and his or her heel was valgus, the child was asked to stand on tiptoes. In the tiptoes test, the absence of heel inversion indicates a rigid FF, while the disappearance of the collapse of the arch of the foot and the valgus of the rear foot indicates FFF [18]. Detection of increase in the medial angle between the long axes of the first metatarsal and the proximal phalanx of the great toe implied a hallux valgus deformity [19].

\section{Radiological investigations}

Lateral weight-bearing $\mathrm{x}$-ray of the feet was done for cases with flat foot, anteroposterior (AP) view of the pelvis for cases of in-toeing and limb discrepancy, and fulllength lower limb anteroposterior $\mathrm{x}$-ray films were taken for cases of limb discrepancy or knee deformity.

\section{Statistical analysis}

All data were tabulated, coded, and analyzed using STATA/SE version 11.2 (College Station, TX). The collected data were tabulated as mean \pm standard deviation (SD), range (for numerical data) and frequency and percentage (for categorical data). Comparisons between the different study groups were performed using the Student $t$-test ( $\mathrm{t}$ ) to compare the groups regarding the numerical 
data. The chi-square test $\left(\chi^{2}\right)$ or the Fisher exact test (FET) was used to compare the categorical data as appropriate. A statistical significance is considered when a $P$-value was $\leq 0.05$.

\section{Results}

This study included 4689 children. Their ages ranged between 6 and 12 years. About half of them (51.31\%) were girls, $48.69 \%$ were boys, $49.18 \%$ were from rural areas, and $50.82 \%$ were from urban areas. The means of their weight and heights were $32.13 \pm 9.9 \mathrm{~kg}$ and 134.29 $\pm 11.05 \mathrm{~cm}$, respectively. Only 94 children $(2 \%)$ were underweight, 3845 (82\%) showed normal weight, 422 (9\%) were overweight, and 328 (7\%) were obese. Less than one-quarter of the children (16.61\%, 779 children) had LL deformity, and only $2.62 \%$ had a history of musculoskeletal (MUS) pain. Three children $(0.06 \%)$ had a significant leg length discrepancy. Four $(0.09 \%)$ children had genu varum. Five children $(0.11 \%)$ had genu valgum. Thirty-five children $(0.75 \%)$ had genu recurvatum. Fortynine children (1.04\%) had in-toeing. Seven hundred and seven children (15.08\%) had flat foot (FF) (in which $13.86 \%$ had FFF and $1.22 \%$ had rigid FF). Eleven children $(0.23 \%)$ had pes cavus. Three children $(0.06 \%)$ had hallux varus. Five children $(0.11 \%)$ had hallux valgus (Table 1$)$. When we stratified children's ages, we found that GVR was equally distributed while FF was more presented at the age of 6 to 7 years, GVL at the age of 7 to 8 years, genu recurvatum at the age of 7 to 8 years, in-toeing at the age of 6 to 7 years, LL discrepancy at the age of 8 to 9 years, pes cavus at the age of 8 to 12 years, hallux valgus at the age of 11 to 12 years, and hallux varus at the age of 8 to 9 years. From children with FF, 21 children $(2.97 \%)$ had in-toeing, 11 children $(1.55 \%)$ had genu recurvatum, 4 children $(0.56 \%)$ had hallux valgus, and 1 child $(0.14 \%)$ had hallux varus; from children with pes cavus, 7 children $(63.64 \%)$ had in-toeing; from children with hallux varus, 1 child (33.33\%) had in-toeing and 1 child (33.33\%) had FF; from children with hallux valgus, 4 children $(80.0 \%)$ had FF and 1 child $(20.0 \%)$ had intoeing; from children who had in-toeing, twenty-one children (42.86\%) had FF, 7 children (14.29\%) had pes cavus, 4 children $(8.16 \%)$ had genu recurvatum, 1 child (2.04\%) had $H$. varus, 1 child $(2.04 \%)$ had $H$. valgus, and 1 child (2.04\%) had genu varum; and from those who had genu varum, one child $(75.0 \%)$ had in-toeing. There were highly statistically significant relations between FF and age, sex, residence, musculoskeletal pain, weight, and height; all $P$-values were less than 0.001 (Table 2). There were statistically significant relations between intoeing, age $\left(P^{<} 0.001\right)$, musculoskeletal pain $\left(P^{<} 0.001\right)$, weight $\left(P^{<} 0.001\right)$, and height $\left(P^{<} 0.001\right)$ (Table 3). Also there were highly statistically significant relations between musculoskeletal (MUS) pain and pes cavus and leg length discrepancy; all $P$-values were less than 0.001 (Fig. 1). There were statistically significant relations

Table 1 Clinical data of the studied children

\begin{tabular}{|c|c|c|c|}
\hline Variable & Range & & Mean \pm SD \\
\hline Weight (kg) & $18-85$ & & $32.13 \pm 9.9$ \\
\hline Height (cm) & $110-160$ & & $134.29 \pm 11.05$ \\
\hline Variable & & $\mathrm{No}=4689$ & $(100.0) \%$ \\
\hline \multirow[t]{5}{*}{$\mathrm{BMI}\left(\mathrm{kg} / \mathrm{m}^{2}\right)$} & Mean $\pm S D$ (range) & $17.48 \pm 3.4(11.42-35.38)$ & \\
\hline & Underweight ( $<5^{\text {th }}$ percentile) & 94 & 2 \\
\hline & Normal weight $\left(5-<85^{\text {th }}\right.$ percentile) & 3845 & 82 \\
\hline & Overweight ( $85-<95^{\text {th }}$ percentile) & 422 & 9 \\
\hline & Obese ( $\geq 95^{\text {th }}$ percentile) & 328 & 7 \\
\hline \multirow[t]{2}{*}{ MUS pain } & No & 4566 & 97.38 \\
\hline & Yes & 123 & 2.62 \\
\hline Genu varum & & 4 & 0.09 \\
\hline Genu valgum & & 5 & 0.11 \\
\hline Genu recurvatum & & 35 & 0.75 \\
\hline FFF & & 650 & 13.86 \\
\hline Rigid FF & & 57 & 1.22 \\
\hline Pes cavus & & 11 & 0.23 \\
\hline In-toeing & & 49 & 1.04 \\
\hline Hallux varus & & 3 & 0.06 \\
\hline Hallux valgus & & 5 & 0.11 \\
\hline
\end{tabular}

SD standard deviation, $\mathrm{kg}$ kilogram, $\mathrm{cm}$ centimeter, BMI body mass index, $\mathrm{kg} / \mathrm{m}^{2}$ kilograms per square meter, MUS musculoskeletal, $F F F$ flexible flat foot, $F F$ flat foot 
Table 2 Relations between the flat foot, demographic, and clinical findings among the studied children

\begin{tabular}{|c|c|c|c|c|c|c|c|}
\hline \multirow[t]{2}{*}{ Variable } & & \multicolumn{2}{|c|}{ FF (no.=707) } & \multicolumn{2}{|c|}{ No FF (no.=3982) } & \multirow[t]{2}{*}{ Test } & \multirow[t]{2}{*}{$P$} \\
\hline & & No. & $\%$ & No. & $\%$ & & \\
\hline Age (years) & Mean \pm SD (range) & \multicolumn{2}{|c|}{$7.79 \pm 1.64(6-12)$} & \multicolumn{2}{|c|}{$8.61 \pm 1.71(6-12)$} & $t=11.41$ & $<0.001(\mathrm{HS})$ \\
\hline \multirow[t]{2}{*}{ Sex } & Female & 298 & 42.15 & 2108 & 52.94 & $x^{2}=27.97$ & $<0.001(\mathrm{HS})$ \\
\hline & Male & 409 & 57.85 & 1874 & 47.06 & & \\
\hline \multirow[t]{2}{*}{ Residence } & Rural & 270 & 38.19 & 2036 & 51.13 & $x^{2}=40.23$ & $<0.001(H S)$ \\
\hline & Urban & 437 & 61.81 & 1946 & 48.87 & & \\
\hline \multirow[t]{2}{*}{ MUS pain } & No & 596 & 596 & 3970 & 99.70 & $x^{2}=557.36$ & $<0.001(\mathrm{HS})$ \\
\hline & Yes & 111 & 15.70 & 12 & 0.30 & & \\
\hline Weight (kg) & Mean \pm SD (range) & \multicolumn{2}{|c|}{$33.99 \pm 8.61(18.5-85)$} & \multicolumn{2}{|c|}{$32.23 \pm 10.01(18-85)$} & $t=4.24$ & $<0.001(\mathrm{HS})$ \\
\hline Height (cm) & Mean \pm SD (range) & \multicolumn{2}{|c|}{$130.8 \pm 10.2(112-154)$} & \multicolumn{2}{|c|}{$134.61 \pm 11.07(110-160)$} & $t=8.23$ & $<0.001(\mathrm{HS})$ \\
\hline \multirow[t]{4}{*}{ BMI $\left(\mathrm{kg} / \mathrm{m}^{2}\right)$} & Underweight ( $<5^{\text {th }}$ percentile) & 17 & 2.40 & 77 & 1.93 & $x^{2}=473.16$ & $<0.001(\mathrm{HS})$ \\
\hline & Normal weight $\left(5-<85^{\text {th }}\right.$ percentile $)$ & 402 & 56.86 & 3443 & 86.46 & & \\
\hline & Overweight (85-<95 ${ }^{\text {th }}$ percentile) & 116 & 16.41 & 306 & 7.68 & & \\
\hline & Obese $\left(\geq 95^{\text {th }}\right.$ percentile) & 172 & 24.33 & 156 & 3.92 & & \\
\hline
\end{tabular}

FF flat foot, SD standard deviation, MUS musculoskeletal, $\mathrm{kg}$ kilogram, $\mathrm{cm}$ centimeter, $B M \mathrm{l}$ body mass index, $\mathrm{kg} / \mathrm{m}^{2} \mathrm{kilograms}$ per square meter, $P$-value $\leq 0.001$ highly significant

between growth percentile and in-toeing $(P=0.005)$, genu recurvatum $(P=0.009)$, genu valgum $(P=0.046)$, pes cavus $(P=0.02)$, and FF $\left(P^{<} 0.001\right)$ and insignificant relation with genu varum $(P=0.14)$ (Fig. 2$)$.

\section{Discussion}

This study explored FF in $15.08 \%$ of school children in close to the result of Sadeghi et al. [20] being 17\% of 667 Iranian children. Our study demonstrated that there was a higher prevalence in males with a statistically significant difference in similarity to Kharbuja and Dhungel
[21] in their study of 5-10 years Nepalese children despite Bogut et al. [22] denied any relation between gender and flat foot in their study of 426 Slavonian children of the same age group. This contradiction may be due to their small sample size. Moreover, we identified a highly significant relation between FF and age in similarity to Alsuhaymi et al. [7], but Hazzaa et al. [23] concluded insignificant relation in their study on 150 children only. This work emphasized a highly significant relation between flat foot and BMI in similarity with Suciati et al. [24] and Chen et al. [25]. We evinced a highly significant

Table 3 Relations between in-toeing, demographic, and clinical findings among the studied children

\begin{tabular}{|c|c|c|c|c|c|c|c|}
\hline \multirow[t]{2}{*}{ Variable } & & \multicolumn{2}{|c|}{ In-toeing (no.=49) } & \multicolumn{2}{|c|}{ No in-toeing $($ no. $=4640)$} & \multirow[t]{2}{*}{ Test } & \multirow[t]{2}{*}{$P$} \\
\hline & & No. & $\%$ & No. & $\%$ & & \\
\hline Age (years) & Mean \pm SD (range) & \multicolumn{2}{|c|}{$6.77 \pm 1.22(6-12)$} & \multicolumn{2}{|c|}{$8.73 \pm 1.66(6-12)$} & $t=8.24$ & $<0.001(\mathrm{HS})$ \\
\hline \multirow[t]{2}{*}{ Sex } & Female & 21 & 42.86 & 2385 & 51.4 & \multirow[t]{2}{*}{$x^{2}=1.42$} & \multirow[t]{2}{*}{0.23} \\
\hline & Male & 28 & 57.14 & 2255 & 48.6 & & \\
\hline \multirow[t]{2}{*}{ Residence } & Rural & 26 & 53.06 & 2280 & 49.14 & \multirow[t]{2}{*}{$x^{2}=0.30$} & \multirow[t]{2}{*}{0.58} \\
\hline & Urban & 23 & 46.94 & 2360 & 50.86 & & \\
\hline \multirow[t]{2}{*}{ MUS pain } & No & 42 & 85.71 & 4523 & 97.35 & \multirow[t]{2}{*}{ FET } & \multirow[t]{2}{*}{$<0.001(\mathrm{HS})$} \\
\hline & Yes & 7 & 14.29 & 123 & 2.65 & & \\
\hline Weight (kg) & Mean \pm SD (range) & \multicolumn{2}{|c|}{$26.48 \pm 6.91(18.5-52)$} & \multicolumn{2}{|c|}{$32.72 \pm 9.98(18-85)$} & $t=4.36$ & $<0.001(\mathrm{HS})$ \\
\hline Height (cm) & Mean \pm SD (range) & \multicolumn{2}{|c|}{$124.74 \pm 7.75(112-152)$} & \multicolumn{2}{|c|}{$135.28 \pm 10.86(110-160)$} & $\mathrm{t}=6.77$ & $<0.001(\mathrm{HS})$ \\
\hline \multirow[t]{4}{*}{$\mathrm{BMI}\left(\mathrm{kg} / \mathrm{m}^{2}\right)$} & Underweight ( $<5^{\text {th }}$ percentile) & 4 & 8.16 & 90 & 1.94 & \multirow[t]{4}{*}{$x^{2}=12.93$} & \multirow[t]{4}{*}{$0.005(\mathrm{~S})$} \\
\hline & Normal weight $\left(5-<85^{\text {th }}\right.$ percentile) & 33 & 67.35 & 3812 & 82.16 & & \\
\hline & Overweight $\left(85-<95^{\text {th }}\right.$ percentile) & 7 & 14.29 & 415 & 8.94 & & \\
\hline & Obese ( $\geq 95^{\text {th }}$ percentile) & 5 & 10.20 & 323 & 6.96 & & \\
\hline
\end{tabular}




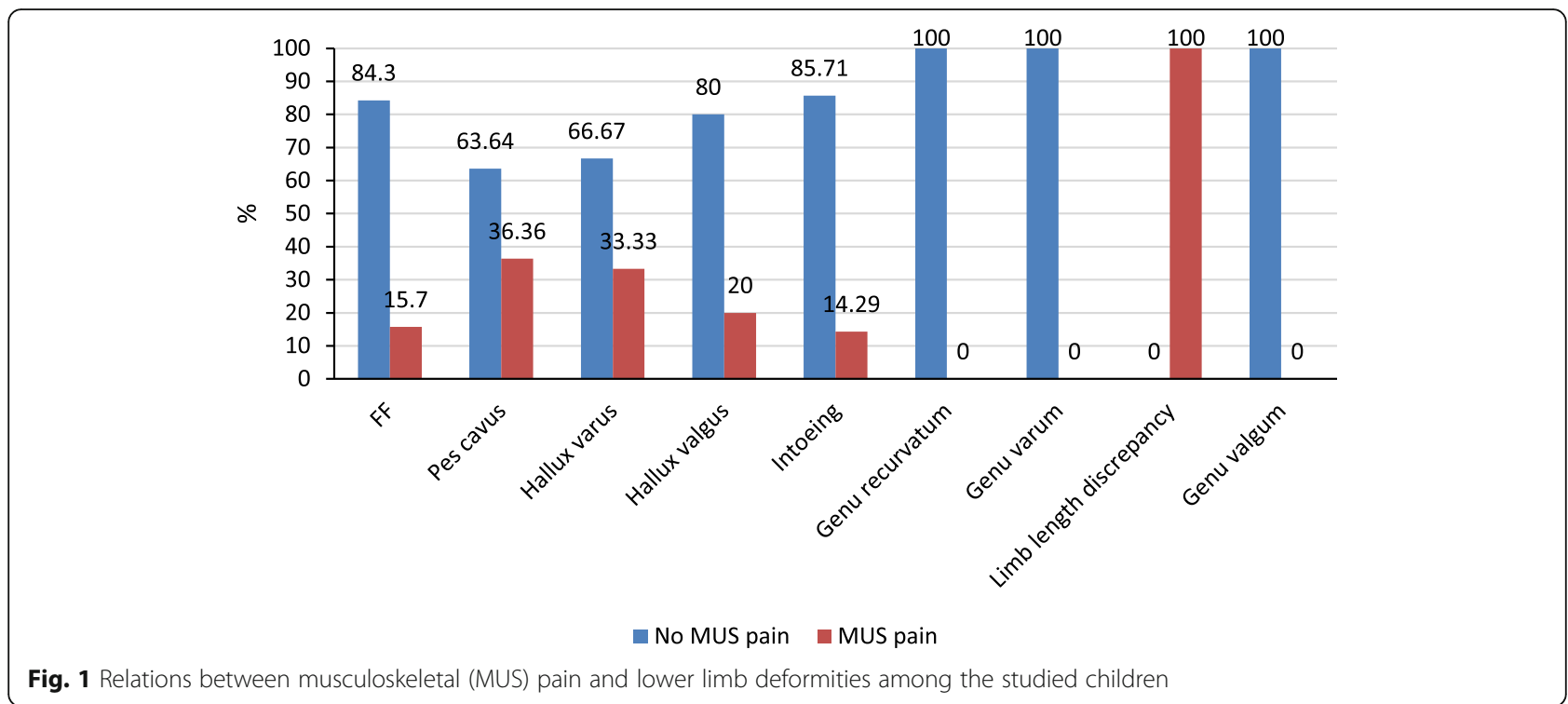

relation between FF and lower extremity pain in line with Abich et al. [26] in their study on Ethiopian children. Pain could be argued to altered stress distribution on the lower extremity parts. Noteworthy, FFF and rigid FF were $13.86 \%$ and $1.22 \%$, respectively, and accounted for $91.94 \%$ and $8.06 \%$ of the positive cases, respectively, so we were close to Ali et al. [27], who found the prevalence of FFF in Pakistani children was $89.6 \%$, and prevalence of rigid FF was $10.4 \%$ of flat foot cases. Sonia et al. [28] in their study of Tunisian children and Ezema et al. [29] in their study of Nigerian primary school students found bilateral FF prevalence in flat foot cases was $75 \%$ and $91.5 \%$, whereas bilateral FF was present in $90.8 \%$ of our flat foot cases. We demonstrated that the prevalence of pes cavus was $0.23 \%$; this was in the vicinity with Bafor and Chibuzom [30], Chou et al. [31], Yoosefinejad and Ghalamghash [32], and Bogut et al. [21], who found that the prevalence of pes cavus in children was $0.7 \%$, $1.32 \%, 2.5 \%$, and $3.68 \%$ respectively. Another point of similarity with them when our study demonstrated that there were statistically insignificant relations between pes cavus, age, sex, residence, weight, and height. On the other hand, we disagreed with Kharbuja and Dhungel [20] who found pes cavus in $25.5 \%$ of 157 children. This contradiction with higher percent may be due to their small sample compared with our study and terrain difference between the two countries. On the other hand, we are agreed with them when we found significant

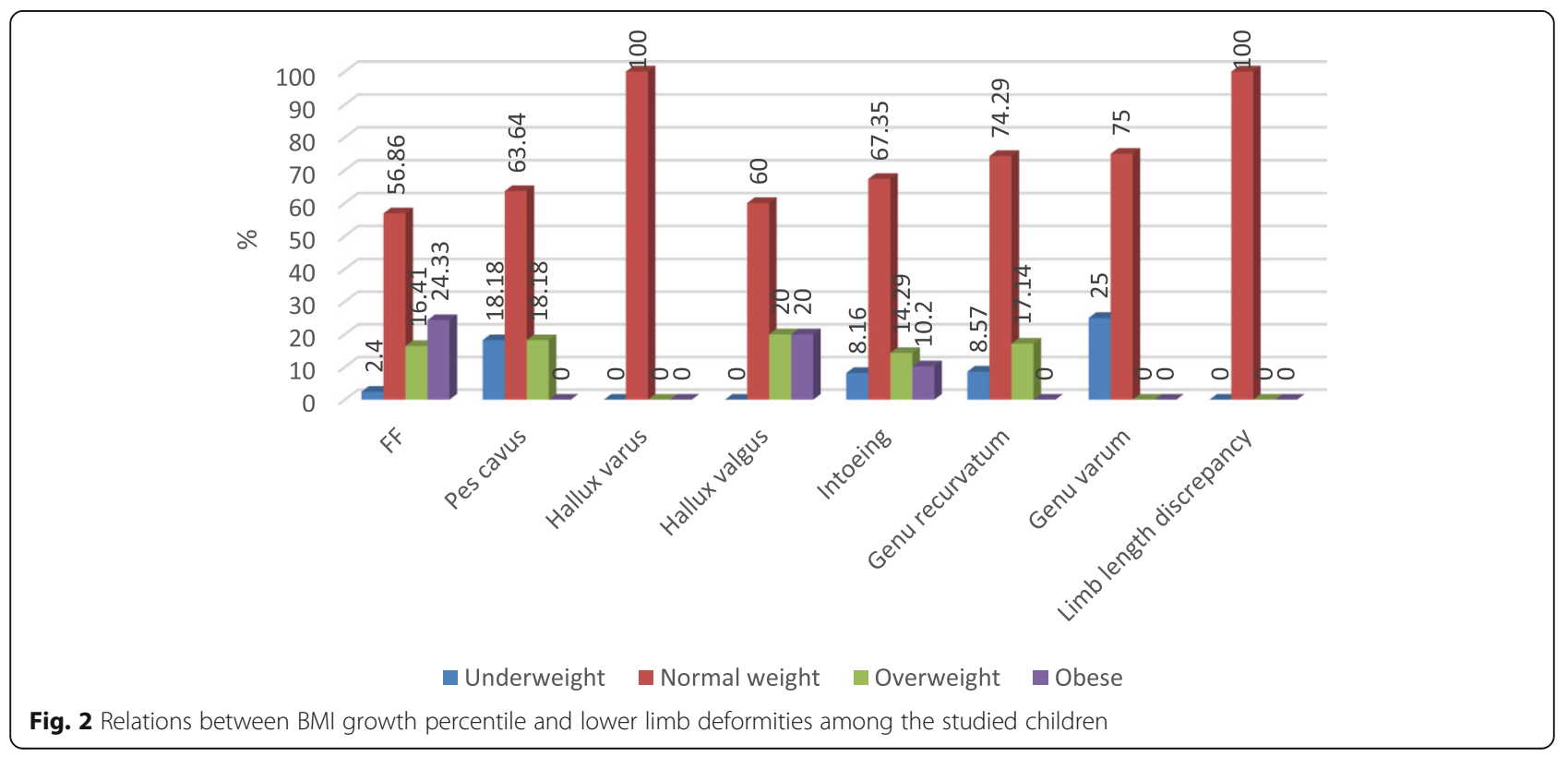


relation between pes cavus and LL pain. We found that the prevalence of hallux valgus was $0.11 \%$, in proximity to the results of Bafor and Chibuzom [30], who found the prevalence was $0.6 \%$ among Nigerian school children between 5 and 13 years, and Chou et al. [31] who found the prevalence was $1.40 \%$ among Chinese students. We detected the prevalence of genu varum (GVR) deformity was $0.09 \%$ in discrepancy with Udoaka et al. [33] who found GVR in $4.6 \%$ of their eight hundred Nigerian children of the same age group. This discrepancy could be attributed to different ethnicity. Although we disagreed with Karimi et al. [34] who documented the prevalence of GVR was $7.9 \%$ in three thousand Iranian children, we agreed with them regarding the insignificant relation between GVR and age. We revealed an insignificant relation between GVR and BMI, supporting the result of Bafor et al. [35] who denied any effect of BMI on the tibiofemoral angle. We emphasized insignificant relation between GVR and gender in line with Zakeri et al. [36] in their study of 383 Iranian children between 6 and 13 years. We found that the prevalence of GVL was $0.11 \%$, but we disagreed with Ciaccia et al. [37], who found it in $7.1 \%$ of 1050 Brazilian students between 5 and 13 years. Our study demonstrated a significant relation between GVL and BMI despite insignificant relation between GVL, age, and gender in agreement with Shapouri et al. [38] in their study of 1450 Iranian children although we disagreed with Zakeri et al. [36] who found significant relations between GVL, age, and gender. Genu recurvatum was noticed in $0.75 \%$ ( 35 children) of our students with significant relations with height and BMI in contrast to Souza et al. [39] in their study of 6-18-year old school students in Brazil [36]. Furthermore, we found a significant LLD of more than $2 \mathrm{~cm}$ in $0.06 \%$ of our children, but we disagreed with Drnach et al. [40], who found it in $6.67 \%$ of 42 girls and 63 boys between 8 and 12 years. There was a significant relation between LLD and the presence and the presence of musculoskeletal pain in agreement with Rannisto et al. [41]. Our work explored that in-toeing deformity was noticed in $1.04 \%$ of our students in proximity to the result of Altinel et al. [42] being $5.9 \%$. However, we disagreed with them as this deformity was bilateral in $76.1 \%$ of their children while it was unilateral in $71.4 \%$ of ours. This discrepancy could be attributed to different age groups. Conversely, Verch et al. [43] found the prevalence of in-toeing gait was calculated to be $16.3 \%$ among their children between 1 and 14 years and unilateral in-toeing being much more frequent, but their higher rate might be due to different method of detection of in-toeing by pressure measurement platform and different age group, but they supported our finding of a highly significant relation between age and in-toeing. Noteworthy, we found significant relations between in-toeing, percentile, and musculoskeletal pain in consistence with Perotti et al. [44].
Some limitations were present in our study as it was conducted in only one governorate and the study results may not be generalizable in addition to absence of diagnostic modalities used for diagnosis of malalignment like foot print and pressure measurement platform. Also absence of complete study of spinal deformity and its hidden role.

\section{Conclusions}

Lower limb deformities are a considerable problem in primary school students that need early diagnosis because it could affect child's future, health and career. Further studies are needed to investigate spinal deformity, vit D level, calcium level, foot wear, and school bag weight as hidden factors.

\section{Abbreviations \\ LL: Lower limb; FF: Flat foot; FFF: Flexible flat foot; Rigid FF: Rigid flat foot; TFA: Tibiofemoral angle; ICD: Intercondylar distance; IMD: Intermalleoar distance; LLD: Leg length discrepancy; BMI: Body mass index; CDC: Centers for Disease Control and Prevention; ASIS: Anterior superior iliac spine; PI: Plantar arch index; AP: Anteroposterior; MUS: Musculoskeletal; HV: Hallux valgus; GVR: Genu varum; GVL: Genu valgum}

\section{Acknowledgements}

We acknowledge all the participants and medical staff who help us in this study.

\section{Authors' contributions}

All authors have read and approved the final manuscript. Idea suggestion, put the study design: SG and NH. Data collection and analysis: AD and AA. Manuscript writing and final revision: SG and NH. The content of the manuscript has not been published or submitted for publication elsewhere.

\section{Funding}

The study did not receive any public or governmental funding.

Availability of data and materials

The datasets used and/or analyzed during the current study are available from the corresponding author on reasonable request.

\section{Declarations}

\section{Ethics approval and consent to participate}

Done, the committee's reference number: 2-2018, date: 28-2-2018

Written consents according to Helsinki Declaration were taken from all patients and control subjects prior to participation in the study that was approved by the ethical committee of Faculty of Medicine, Benha University.

\section{Consent for publication}

Not applicable.

\section{Competing interests}

Dr. Sahar Saad Ganeb is Editor in chief in Egyptian Rheumatology and Rehabilitation. The other authors declare that they have no competing interests.

\section{Author details}

${ }^{1}$ Rheumatology, Rehabilitation \& Physical Medicine Department, Faculty of Medicine, Benha University, Benha 13115, Egypt. ${ }^{2}$ Community Medicine, Faculty of Medicine, Benha University, Benha, Egypt. ${ }^{3} \mathrm{MBBCh}$ Faculty of Medicine, Tanta University, Benha, Egypt. 
Received: 12 June 2021 Accepted: 18 August 2021

Published online: 16 November 2021

\section{References}

1. Latalski M, Bylina J, Fatyga M, Repko M, Filipovic M, Jarosz MJ, Borowicz KB, Matuszewski Ł, Trzpis T (2013) Risk factors of postural defects in children at school age. Ann Agri Environ Med 20(3):583-587

2. Jones S, Khandekar S, Tolessa E (2013) Normal variants of the lower limbs in pediatric orthopedics. Int J Clin Med 4:12-17

3. Brianezi L, Cajazeiro D, Maifrino L (2011) Prevalence of postural deviations in school of education and professional practice of physical education. J Morhol Sci 28(1):35-36

4. Kaspiris A, Zaphiropoulou C, Vasiliadis E (2013) Range of variation of genu valgum and association with anthropometric characteristics and physical activity: comparison between children aged 3-9 years. J Pediatr Orthop B 22(4):296-305. https://doi.org/10.1097/BPB.0b013e328360f9a5

5. Arazi M, Oğün TC, Memik R (2001) Normal development of the tibiofemoral angle in children: a clinical study of 590 normal subjects from 3 to 17 years of age. J Pediatr Orthop. 21(2):264-267. https://doi.org/10.1097/01241398-2 00103000-00027

6. Calvete AS (2007) The relationship between postural changes and sports injuries in obese children and adolescents. Driving. Physical Education Magazine. UNESP 10(2):67-72

7. Alsuhaymi AM, Almohammadi FF, Alharbi OA, Alawfi AH, Olfat MM, Alhazmi OA, Khoshhal KI (2019) Flatfoot among school-age children in Almadinah Almunawwarah: Prevalence and risk factors. J Musculoskelet Surg Res 3(2): 204. https://doi.org/10.4103/jmsr.jmsr_89_18

8. Steginsky B, Vora A (2017) What to do with the spring ligament. Foot Ankle Clin 22(3):515-527. https://doi.org/10.1016/j.fcl.2017.04.005

9. Neal BS, Griffiths IB, Dowling GJ, Murley GS, Munteanu SE, Smith MMF et al (2014) Foot posture as a risk factor for lower limb overuse injury: a systematic review and meta-analysis. J Foot Ankle Res 7(1):1-13

10. Angin S, Mickle KJ, Nester CJ (2018) Contributions of foot muscles and plantar fascia morphology to foot posture. Gait Posture 61:238-242. https:// doi.org/10.1016/j.gaitpost.2018.01.022

11. Quka N, Stratoberdha D, Selenica R (2015) Risk factors of poor posture in children and its prevalence. Acad J Interdiscip Stud 4(3):97-102

12. No reference provide.

13. -Nordic questionnaires for the analysis of musculoskeletal symptoms. Appl Ergon. 1987;18(3):233-7.

14. -Kuczmarski RJ (2000). CDC growth charts: United States (No. 314). US Department of Health and Human Services, Centers for Disease Control and Prevention, National Center for Health Statistics.

15. Omololu B, Tella A, Ogunlade SO, Adeyemo AA, Adebisi A, Alonge TO et al (2003) Normal values of knee angle, intercondylar and intermalleolar distances in Nigerian children. West Afr J Med 22(4):301-304. https://doi. org/10.4314/wajm.v22i4.28051

16. Guichet JM, Spivak JM, Trouilloud P et al (1991) Lower limb-length discrepancy an epidemiologic study. Clin Orthop 272:235-241

17. Cappello T, Song KM (1998) Foot deformities in infants and children. Padiatr Clin North AM 33:14411-14427

18. Rodriguez N, Volpe RG (2010) Clinical diagnosis and assessment of the pediatric pes planovalgus deformity. Clin Podiatr Med Surg 27(1):43-58. https://doi.org/10.1016/j.cpm.2009.08.005

19. Alazzawi S, Sukeik M, King D, Vemulapalli K (2017) Foot and ankle history and clinical examination: a guide to everyday practice. World J Orthop 8(1): 21-29. https://doi.org/10.5312/wjo.v8.i1.21

20. Sadeghi-Demneh E, Azadinia F, Jafarian F, Shamsi F, Melvin JM, Jafarpishe M et al (2016) Flatfoot and obesity in school-age children: a cross-sectional study. Clin Obes 6(1):42-50. https://doi.org/10.1111/cob.12125

21. Kharbuja R, Dhungel S (2017) Prevalence Of Pes Cavus And Pes Planus Among School Going Children Of Bhaktapur District, Nepal. Nepal Med Coll J 19(1):9-12

22. Bogut I, Popović Ž, Tomac Z, Matijević V, Radmilović G (2019) Prevalence of Foot Deformities in Young Schoolchildren in Slavonia. Acta Clinica Croatica 58(2):288-294

23. Hazzaa HH, El-Meniawy GH, Ahmed SE, Bedier MB (2015) Correlation between gender and age and flat foot in obese children. Trends Appl Sci Res 10(4):207-215. https://doi.org/10.3923/tasr.2015.207.215

24. -Suciati, T., Adnindya, M. R., Septadina, I. S., Pratiwi, P. P. (2019). Correlation between flat feet and body mass index in primary school students. In
Journal of Physics: Conference Series (Vol. 1246, No. 1, p. 012063). IOP Publishing

25. Chen JP, Chung MJ, Wang MJ (2009) Flatfoot prevalence and foot dimensions of 5-to 13-year-old children in Taiwan. Foot Ankle Int 30(4): 326-332. https://doi.org/10.3113/FAl.2009.0326

26. Abich Y, Mihiret T, Yihunie Akalu T, Gashaw M, Janakiraman B (2020) Flatfoot and associated factors among Ethiopian school children aged 11 to 15 years: A school-based study. PLoS ONE 15(8):e0238001. https://doi.org/1 0.1371/journal.pone.0238001

27. Ali M, AsadUllah M, Amjad I (2013) Prevalence of the flat foot in 6-10 years old school going children. Rawal Med J 38(4):385-387

28. Sonia J, Nadia L, Manel A, Samia F, Mohamed BR, Walid O, Afif Z, Faycel K (2015) Children Flat Foot and Lower Limb Rotational Profile: A CrossSectional Descriptive Study. Open J Orthop 5(10):326-335. https://doi.org/1 0.4236/ojo.2015.510044

29. Ezema Cl, Abaraogu UO, Okafor GO (2014) Flat foot and associated factors among primary school children: a cross-sectional study. Hong Kong Physiother J 32(1):13-20. https://doi.org/10.1016/j.hkpj.2013.05.001

30. Bafor A, Chibuzom CN (2020) Foot and ankle abnormalities among a cohort of Nigerian school children: an epidemiological study. Int Orthop 44(6): 1169-1175. https://doi.org/10.1007/s00264-020-04568-Z

31. Chou LW, Chen FF, Lo SF, Yang PY, Meng NH, Lin CL et al (2009) The prevalence of four common pathomechanical foot deformities in primary school students in Taichung county. Mid Taiwan J Med 14(1):1-9

32. -Yoosefinejad A. K. and Ghalamghash R. (2014). The Evaluation and prevalence of foot problems among Iranian students using "alfoots" company scanner.

33. Udoaka Al, Olotu J, Oladipo GS (2012) The prevalence of genu varum in primary school children in Port Harcourt, Nigeria. Scientia Africana 11(2)

34. Karimi M, Kashefipour A, Yousfnejad Z (2005) The prevalence of genu varum and genu valgum in primary school children in Iran 2003-2004. J Med Sci 5(1):52-54

35. Bafor A, Omota B, Ogbemudia AO (2012) Correlation between clinical tibiofemoral angle and body mass index in normal Nigerian children. Int Orthop 36(6):1247-1253. https://doi.org/10.1007/s00264-011-1451-z

36. Zakeri Y, Baraz S, Gheibizadeh M, Bijan Nejad D, Latifi SM (2016) Prevalence of musculoskeletal disorders in primary school students in Abadan-Iran in 2014. Int J Pediatr 4(1):1215-1223

37. Ciaccia MCC, Pinto CN, Golfieri FDC, Machado TF, Lozano LL, Silva JMS, Rullo VEV (2017) Prevalence of genu valgum in public elementary schools in the city of Santos (SP), Brazil. Revista Paulista de Pediatria 35(4):443-447. https:// doi.org/10.1590/1984-0462/;2017;35;4;00002

38. Shapouri J., Aghaali M., Aghaei M., Iranikhah A., Ahmadi R. and Hovsepian S (2019) Prevalence of lower extremities' postural deformities in overweight and normal weight school children. Iran J Pediatr, 29(5):e89138.

39. Souza AA, Ferrari GLDM, Júnior JPDS, Silva LJD, Oliveira LCD, Matsudo VKR (2013) Association between knee alignment, body mass index and physical fitness variables among students: a cross-sectional study. Revista brasileira de ortopedia 48(1):46-51. https://doi.org/10.1016/j.rbo.2011.10.001

40. Drnach M, Kreger A, Corliss C, Kocher D (2012) Limb length discrepancies among 8-to 12-year-old children who are developing typically. Pediatr Phys Ther 24(4):334-337. https://doi.org/10.1097/PEP.0b013e3182691c48

41. -Rannisto, S., Okuloff, A., Uitti, J., Paananen, M., Rannisto, P. H., Oalmivaara, A. et al (2015). Leg-length discrepancy is associated with low back pain among those who must stand while working. BMC Musculoskelet Disord, 16(1), 1-7.

42. Altinel L, Köse KC, Aksoy Y, Işik C, Erğan V, Ozdemir A (2007) Hip rotation degrees, intoeing problem, and sitting habits in nursery school children: an analysis of 1,134 cases. Acta Orthop Traumatol Turc. 41(3):190-194

43. Verch R, Hirschmüller A, Müller J, Baur H, Mayer F, Müller S (2018) Is in-toing gait physiological in children? - Results of a large cohort study in 5910 healthy (pre-) school children. Gait Posture 66:70-75. https://doi.org/10.101 6/j.gaitpost.2018.08.019

44. -Perotti LR, Abousamra O, Del Pilar Duque Orozco M, Rogers KJ, Sees JP, Miller F. J Child Orthop. 2018;12(3):218-226. doi: 1

\section{Publisher's Note}

Springer Nature remains neutral with regard to jurisdictional claims in published maps and institutional affiliations. 